\title{
Seeking a Tool to Assess Consumer Involvement in the Pharmaceutical Area: the Case of Consumer Involvement Profile as a Popular Scale
}

\author{
Fatemeh Momeni \\ Hamadan University of Medical Sciences \\ Maryam Rangchian ( $\nabla$ m.rangchian89@gmail.com) \\ Hamadan University of Medical Sciences \\ Sara Ataei \\ Hamadan University of Medical Sciences \\ Mohsen Moradi \\ Iranian Academy of Statistical Analysis
}

\section{Research Article}

Keywords: Consumer Involvement Profile, Pharmaceuticals, Psychometric evaluation, Validity, Reliability, Goodness of fit, HTMT

Posted Date: February 7th, 2022

DOI: https://doi.org/10.21203/rs.3.rs-1132247/v1

License: () (1) This work is licensed under a Creative Commons Attribution 4.0 International License. Read Full License 


\section{Abstract}

Background Involvement is one of the most important determinants of consumers' behaviour. Considering the special position of the pharmaceutical products in public health and peace of mind, awareness from consumer involvement toward these products is very helpful for health system policy makers. To this end, access to a valid reliable tool to evaluate this concept is of great importance. Therefore, the present study aimed to evaluate the psychometric properties of the Persian version of a popular related questionnaire, naming Consumer Involvement Profile (CIP), to be used to assess consumers' involvement regarding pharmaceutical products.

Methods This cross-sectional study was conducted from January 2020 to March 2021 in Hamadan, Iran. Data were gathered using the 16 -item CIP questionnaire with sentences adapted for the pharmaceutical products. Content validity, internal consistency, overtime reliability based on the test-retest method, construct validity (including convergent and discriminant validity), and goodness of fit were evaluated for the questionnaire.

Results Data obtained from 357 respondents underwent analysis. Overtime reliability was confirmed by a coefficient equal to 0.836 ( $p$-value= 0.000 ). Cronbach's alpha was only lower than 0.6 for the "risk probability" dimension. Regarding the convergent validity, two items had loading factors less than 0.5 , which were omitted from the modified model. All CR values were higher than the corresponding AVE values. However, for two dimensions CR was less than 0.7. Although, based on the MSV, ASV and Fornell-Larcker test, importance, risk probability and risk importance, as well as importance with pleasure showed some overlaps, the discriminant validity was confirmed by HTMT. Goodness of fit indices were completely satisfying for the both primary and modified models.

Conclusion The CIP questionnaire showed an acceptable performance to measure the consumers' involvement in pharmaceutical products. This is the first study to introduce a valid tool based on a well-known scale for measuring consumer involvement in the field of medicines. Such instruments facilitate to manufacturers and policymakers in this field to make informed decisions and promote community health.

\section{Background}

Involvement is a concept of wide usage in the consumer behavior area [1], it is known as one of the most important determinants of consumers' decision-making and behavior [2,3]. One of the definitions provided for the consumer involvement is "the degree to which consumers involve in different aspects of the consumption process" [2]. It is unobservable combination of interest, motivation or arousal [4].

Although several theoretical models have been formed to conceptualize consumer involvement, there is no agreement regarding its meaning [1]. Various scales have been developed to operationalize and quantify its concept; Zaichkowsky's "Personal Involvement Inventory" (PII) [5] and Laurent and Kapferer's “Consumer Involvement Profile" (CIP) [6] are two extensively used examples of them [7, 8]. Some researchers prefer Zaichkowsky's scale because of its unidimensionality [2,9], while Laurent and Kapferer's CIP popularity is thanks to its multidimensional structure [2]. CIP scale includes five dimensions: risk importance, risk probability, hedonic (pleasure), sign and importance/interest.lt has been tested for diverse products such as beer [9], cameras and jeans [10], television sets, shampoo and mattresses [6], cars, clothing, consumer electronic equipment and audio recording [11], food items [2], clothes shopping and makeup [12]. The involvement concept has been examined also in the context of leisure and recreation [13, 14], as well as tourism $[8,15,16]$. However, to our best of knowledge, no study has addressed this concept in the field of pharmaceuticals. Although the decision making regarding medicines that patients buy and use is not made by them, but their opinion may influence the decision [17]. It is probable that patients' involvement about medication affect some of their behaviors, such as the pattern of consumption of medical products [18], and expectations from health system policy makers. Therefore, awareness of patients' mental involvement can help health system policymakers understand and predict patients' expectations, which in turn, requires a proper instrument to measure involvement.

Considering the explained issues, the present study was dedicated to assess a tool, prepared based on the Laurent and Kapferer (CIP) questionnaire, in terms of its validity and reliability for pharmaceutical products.

\section{Methods Study place and time}

The present cross-sectional study was conducted in January 2020 to March 2021 in Hamadan, Iran. The studied population were people with at least 18 years of old, who live in Hamadan.

\section{Instrument selection}

Initially, the related literatue published between 1990 and 2020 were reviewed. However, no comprehensive, standard questionnaire specified for assessing involvement to drugs was found. Therefore general consumer involvement scales were examined and, as was explained before, the Laurent and Kapferer's (CIP) questionnaire was selected because of several reasons; first and foremost, it has a multidimensional structure, which allows researchers to consider various aspects of involvement. Secondly, it is one of the most well-known and popular consumer involvement instruments [11].

The initial version of this questionnaire included 5 dimensions: interest/importance (3 questions), pleasure (3 questions), sign (3 questions), risk probability (3 questions) and risk importance (4 questions). Responses were scored by a five-point Likert scale, including "strongly agree" (score 5), "agree"(score 4), "don’t know" (score 3), "disagree" (score 2) and "strongly disagree" (score 1) [6, 16]. 


\section{Data Analysis}

Data analysis included the descriptive statistical analysis of the participants' characteristics and the evaluation of the instrument validity, reliability and fitness. Descriptive analysis was performed applying the PSPP software. The applied softwares for other analyses have been mentioned in the related sub-section of the method section.

For the analysis performed by PSPP, the missed data were managed using pair-wise deletion. For the other analyses, the missed data were substituted by the median; however it must be explained that the cases having more than $10 \%$ missing data in the main questions were not included in the data analysis.

\section{Investigating the instrument reliability, validity and fitness}

\section{Reliability}

\section{Internal consistency}

The internal consistency is usually evaluated by Chronbach's alpha and Composite Reliability (CR) index. Chronbach's alpha examines the level of relation between responses to various items composing a dimension, without considering the other dimensions of a scale; however, the $\mathrm{CR}$ index assesses that while is included in the measurement model of the total scale. The acceptable value for Chronbach's alpha and also CR is 0.7 . Chronbach's alpha was calculated using PSPP and the CR was calculated by Excel applying the factor loading values obtained by AMOS software.

\section{Over time reliability}

In order to evaluate the overtime reliability of the instrument, test-retest method was conducted, inviting 16 people [19]. The Retest stage was performed 2 weeks after the test phase [20]. Because of the normal distribution of the data, Kendall's tau-b test was used to determine the correlation between the two steps. This test was done using PSPP.

\section{Content validity}

The validity was examined qualitatively and quantitatively using 12 experts' opinions. Content validity Index and Content Validity Ratio are common indices being considered to evaluate content validity. The present study was aimed to assess the contribution of each dimension of the Laurent and Kapferer's CIP questionnaire to the pharmaceutical products involvement. Therefore, experts were not asked about the necessity of the questions. In other words, all dimensions and items were supposed to be included in the data gathering phase of the present study.

Considering the Waltz and, Bausell's method, four criteria, including the clarity, completeness, relevance and scoring of the items were assessed [21]. Then, CVI was calculated and based on its results, some items were revised. If CVI was $\geq 0.79$, the question was acceptable, CVI between $0.79-0.7$ shows the need to correction of the item; items with CVI less than 0.7 are unacceptable [22, 23].

\section{Construct validity}

The Construct validity of the instrument was checked through Confirmatory Factor Analysis (CFA), using AMOS; before that, Kaisere-Meyere-Olkin (KMO) measure of sampling adequacy and Bartlett's test of sphericity were checked in PSPP, to ensure a satisfactory factor analysis.

The Construct validity includes convergent validity and divergent (discriminant) validity; the related results have been elaborated in the following.

\section{Convergent validity}

To confirm convergent validity, several conditions must be met: 1) statistically significant loading factors; 2 ) loading factors equal to or higher than 0.5 ;

3) Average Variance Extracted (AVE) more than 0.5 and 4) CR higher than AVE. These conditions were evaluated in this study; the related findings have been reported in the result section. AMOS was used to elicit the loading factors and their significance and Excel was used to calculate AVE and CR.

\section{Divergent validity}

Four tests were performed to investigate the discriminant validity. The latest standards propounded to pass this kind of validity include: 1) AVE higher than MSV (Maximum Shared Squared Variance); 2) AVE higher than ASV (Average Shared Squared Variance); 3) AVE higher than the square of correlation coefficient with other dimensions (Fornell-Larcker criterion), and 4) HTMT (Heterotrait-monotrait ratio of correlations) less than 0.9. AMOS was used to elicit the loading factors, their significance and items correlation matrix; Excel was used to calculate AVE, ASV, MSV and HTMT.

\section{Fitness}

Fitness indices are very diverse. The most important indices that must be checked include $\chi^{2}$ /df lower than 3 , RMSEA lower than 0.08 , GFI and AGFI higher than 0.8 , and at least three comparative indices (CFI, NFI, IFI, RFI, TLI) higher than 0.9. All of the mentioned indices have been assessed and reported in this study.

\section{Results}


Out of 380 people invited to the study, the questionnaire was completed by 367 ones (response rate= $96.5 \%$ ). Incomplete forms and indifferent cases were eliminated and 357 samples were considered acceptable for analysis.

\section{Respondents' characteristics}

The participants' demographic characteristics are presented in Table 1. The minimum, maximum and median values of age were equal to 18,80 and 40 , respectively. As can be seen, the numbers of the male and female participants were almost the same. High school diploma/associate degree with a frequency near to one third was the most prevalent level of the education. $12.8 \%$ of the participants were working in a job related to the medical/paramedical area. $39.2 \%$ of participants had the average monthly family income about 30 to 60 million Iranian riyals (120-240 US dollars). About $53.8 \%$ of the respondents had at least one patient with chronic disease in their close relatives or themselves were suffering from such diseases (Table 1).

Table 1

Demographic characteristics of the participants $(\mathrm{N}=$ 357)

\begin{tabular}{|c|c|}
\hline Characteristic & n (\%) \\
\hline \multicolumn{2}{|l|}{ Age in years } \\
\hline $18-29$ & $72(20.2)$ \\
\hline $30-39$ & $94(26.3)$ \\
\hline $40-49$ & $85(23.8)$ \\
\hline $50-59$ & $51(14.3)$ \\
\hline$>60$ & $55(15.4)$ \\
\hline \multicolumn{2}{|l|}{ Gender } \\
\hline Male & $171(47.9)$ \\
\hline Female & $186(52.1)$ \\
\hline \multicolumn{2}{|l|}{ Education level } \\
\hline Illiterate & $24(6.7)$ \\
\hline Lower than high school diploma & $53(14.8)$ \\
\hline High school diploma/ associate degree & $116(32.5)$ \\
\hline Bachelor & $111(31.1)$ \\
\hline Higher than bachelor & $54(14.8)$ \\
\hline \multicolumn{2}{|l|}{ Medical/paramedical occupations } \\
\hline Yes & $45(12.6)$ \\
\hline No & $196(54.9)$ \\
\hline not employed & $107(30.0)$ \\
\hline \multicolumn{2}{|l|}{ Family income (US dollar/month) ${ }^{a}$} \\
\hline Less than 40 & $9(2.5)$ \\
\hline 40- Less than 120 & $118(33.1)$ \\
\hline $120-240$ & $140(39.2)$ \\
\hline More than 240 & $86(24.1)$ \\
\hline \multicolumn{2}{|l|}{ Chronic disease } \\
\hline Yes & $192(53.8)$ \\
\hline No & $159(44.5)$ \\
\hline
\end{tabular}

\section{Instrument assessment}

The primary and modified models are shown in Figure 1. The five dimensions of the involvement included interest/importance (IMP), pleasure (PLE), sign (SIG), risk probability (RPR) and risk importance (RIM). 
Findings regarding the scale reliability, validity and fitness have been elaborated in the following.

\section{Content validity}

For 14 out of 16 items, the obtained CVI values set among 0.813 and 0.979 , which pass the minimum acceptable value for the CVI index that is 0.79 [ 22 , 23]. For items 2 and 9, the CVI was less than the acceptable level; these items were modified before being used for data gathering.

\section{Reliability}

\section{Overtime reliability}

A test-retest method was used in order to ensure the overtime reliability of the questionnaire, demonstrating a significant strong correlation with the coefficient equal to 0.836 ( $p$-value= 0.000$)$, which confirms a good over time reliability.

\section{Internal consistency}

The values obtained for Cronbach's alpha and CR are demonstrated in Table 2. Only for the "risk probability", Cronbach's alpha was lower than 0.6. In addition, except for the mentioned dimension and the "risk importance", the CR values matched the 0.7 cut off. All CR values were higher than the corresponding AVE values. 
Table 2

Results obtained for the instrument reliability and convergent validity for the primary and modified models $(\mathrm{N}=357)$

\begin{tabular}{|c|c|c|c|c|c|c|c|c|c|c|}
\hline \multirow[t]{2}{*}{ Item } & \multicolumn{5}{|c|}{ Primary Model } & \multicolumn{5}{|c|}{ Modified Model } \\
\hline & $\mathrm{FL}^{\mathrm{a}}$ & $t-\left.v a\right|^{b}$ & alphac & AVE $^{d}$ & $\mathrm{CR}^{\mathrm{e}}$ & FL & t-val & alpha & AVE & CR \\
\hline \multicolumn{11}{|l|}{ Interest/Importance } \\
\hline 1. Choose of a medicine is an important decision for me. & 0.68 & & \multirow[t]{3}{*}{0.66} & \multirow[t]{3}{*}{43.91} & \multirow[t]{3}{*}{0.70} & 0.68 & & \multirow[t]{3}{*}{0.66} & \multirow[t]{3}{*}{44.09} & \multirow[t]{3}{*}{0.70} \\
\hline 2. I buy medicine very carefully. & 0.77 & 10.60 & & & & 0.77 & 10.57 & & & \\
\hline 3. Taking medicine is an important part of my life. & 0.52 & 8.18 & & & & 0.52 & 8.19 & & & \\
\hline \multicolumn{11}{|l|}{ Pleasure } \\
\hline 4. Getting the medicine I need makes me feel satisfied. & 0.71 & & \multirow[t]{3}{*}{0.64} & \multirow[t]{3}{*}{40.82} & \multirow[t]{3}{*}{0.67} & 0.72 & & \multirow[t]{3}{*}{0.64} & \multirow[t]{3}{*}{41.68} & \multirow[t]{3}{*}{0.68} \\
\hline 5. When I buy medicine for myself, I feel I care about myself. & 0.59 & 8.15 & & & & 0.59 & 8.13 & & & \\
\hline $\begin{array}{l}\text { 6. Access to the medication I need gives me a sense of } \\
\text { calmness. }\end{array}$ & 0.60 & 8.25 & & & & 0.61 & 8.25 & & & \\
\hline \multicolumn{11}{|l|}{ Sign } \\
\hline $\begin{array}{l}\text { 7. According to the brand (manufacturer) of the medicine that } \\
\text { a person chooses, things can be realized about that person. }\end{array}$ & 0.82 & & \multirow[t]{3}{*}{0.76} & \multirow[t]{3}{*}{52.23} & \multirow[t]{3}{*}{0.76} & 0.82 & & \multirow[t]{3}{*}{0.76} & \multirow[t]{3}{*}{52.57} & \multirow[t]{3}{*}{0.76} \\
\hline $\begin{array}{l}\text { 8. People can be evaluated based on the brand } \\
\text { (manufacturer) of the medicine they consume. }\end{array}$ & 0.52 & 8.49 & & & & 0.52 & 8.49 & & & \\
\hline $\begin{array}{l}\text { 9. The brand (manufacturer) of the medicine a person buys } \\
\text { shows what type of person is he/she. }\end{array}$ & 0.79 & 10.13 & & & & 0.79 & 10.12 & & & \\
\hline \multicolumn{11}{|l|}{ Risk probability } \\
\hline $\begin{array}{l}\text { 10. When I choose a drug company, I can never be sure if I } \\
\text { made the right choice. }\end{array}$ & 0.35 & & \multirow[t]{3}{*}{0.54} & \multirow[t]{3}{*}{38.30} & \multirow[t]{3}{*}{0.55} & & & \multirow[t]{3}{*}{0.56} & \multirow[t]{3}{*}{39.70} & \multirow[t]{3}{*}{0.52} \\
\hline $\begin{array}{l}\text { 11. It is not easy for me to choose the right company if the } \\
\text { product of the company I usually use does not exist. }\end{array}$ & 0.64 & 5.41 & & & & 0.63 & & & & \\
\hline 12. Choosing a drug company is a relatively complex task. & 0.62 & 5.36 & & & & 0.62 & 8.60 & & & \\
\hline \multicolumn{11}{|l|}{ Risk importance } \\
\hline $\begin{array}{l}\text { 13. It is not very important to me if I mistakenly buy another } \\
\text { company's medicine instead of the company I intended. }\end{array}$ & 0.32 & & 0.62 & 31.66 & 0.64 & & & 0.65 & 38.39 & 0.65 \\
\hline $\begin{array}{l}\text { 14. If I had to choose between several companies to buy } \\
\text { medicine, I would be very worried about the outcome of my } \\
\text { choice. }\end{array}$ & 0.69 & 5.16 & & & & 0.70 & & & & \\
\hline $\begin{array}{l}\text { 15. Inappropriate choice of the medicine company can harm } \\
\text { a person's health. }\end{array}$ & 0.60 & 5.02 & & & & 0.59 & 8.81 & & & \\
\hline $\begin{array}{l}\text { 16. If I find out after buying medicine that I did not have a } \\
\text { good choice, I will be very upset. }\end{array}$ & 0.57 & 4.94 & & & & 0.56 & 8.45 & & & \\
\hline
\end{tabular}

\section{Construct validity}

As explained before, the suitability of the data to perform CFA was checked using the KMO and the Bartlett's test of sphericity. KMO was 0.724 and the pvalue of the Bartlett's test was 0.000 , which both are in accordance with the needed criteria.

\section{Convergent validity}

First, the primary model underwent the CFA. To reduce the number of the tables, findings regarding convergent validity have also been summarized in Table 2. As seen from the table, the factor loadings of the items 11 and 15 are less than the minimum acceptable value of 0.5 . Therefore, modifications including the elimination of these two items were needed. The final version of the scale after modifications included 5 dimensions, including interest/importance (3 questions); pleasure (3 questions); sign (3 questions); risk probability (2 questions); and risk importance (3 questions). The results for modified model are also reported in Tables 2. As found from the tables, the modified model still faces some problems in terms of the convergent validity. 


\section{Discriminant validity}

In terms of discriminant validity, lack of divergence was observed among importance, risk probability and risk importance, as well as importance with pleasure, based on the values obtained for ASV, MSV and Fornell-Larcker test (Table 3).

Table 3

The results of MSV, ASV and Fornell-Larcker tests for the primary and modified model

\begin{tabular}{|c|c|c|c|c|c|c|c|c|c|c|c|c|c|c|c|c|}
\hline \multirow[t]{2}{*}{ Dimension } & \multicolumn{2}{|c|}{$\begin{array}{l}\text { Number of } \\
\text { items }\end{array}$} & \multicolumn{2}{|l|}{ MSV } & \multicolumn{2}{|l|}{ ASV } & \multicolumn{2}{|c|}{ Interest/importance } & \multicolumn{2}{|c|}{ Pleasure } & \multicolumn{2}{|l|}{ Sign } & \multicolumn{2}{|c|}{$\begin{array}{l}\text { Risk } \\
\text { probability }\end{array}$} & \multicolumn{2}{|c|}{$\begin{array}{l}\text { Risk } \\
\text { importance }\end{array}$} \\
\hline & Prim $^{\dagger}$ & $\operatorname{Mod}^{*}$ & Prim & Mod & Prim & Mod & Prim & Mod & Prim & Mod & Prim & Mod & Prim & Mod & Prim & Mod \\
\hline Importance & 3 & 3 & 0.78 & 0.79 & 0.39 & 0.40 & 0.66 & 0.66 & & & & & & & & \\
\hline Pleasure & 3 & 3 & 0.51 & 0.54 & 0.36 & 0.37 & 0.62 & 0.62 & 0.64 & 0.64 & & & & & & \\
\hline Sign & 3 & 3 & 0.39 & 0.39 & 0.24 & 0.23 & 0.33 & 0.33 & 0.17 & 0.17 & 0.72 & 0.72 & & & & \\
\hline $\begin{array}{l}\text { Risk } \\
\text { probability }\end{array}$ & 3 & 2 & 0.11 & 0.11 & 0.04 & 0.04 & 0.72 & 0.74 & 0.50 & 0.49 & 0.14 & 0.16 & 0.55 & 0.63 & & \\
\hline $\begin{array}{l}\text { Risk } \\
\text { importance }\end{array}$ & 4 & 3 & 0.78 & 0.79 & 0.38 & 0.38 & 0.66 & 0.65 & 0.53 & 0.52 & 0.10 & 0.12 & 0.88 & 0.89 & 0.56 & 0.62 \\
\hline
\end{tabular}

†. Primary model, ${ }^{*}$ : Modified model

HTMT is a relatively new and attractive criterion being considered to assess the discriminant validity of the scales, which was also evaluated in the present research (Table 4). A remarkable finding for the CIP in this research was the acceptable value of HTMT for all dimensions in both primary and modified models, considering the value 0.9 as the HTMT cut off. Some references suggest the cut off equal to 0.85 in case of need to more conservative assessment [24]; if consider the conservative approach, the "risk probability" and "risk importance" are not divergent.

Table 4

The values of HTMT for the primary and modified model

\begin{tabular}{|lllll|}
\hline Primary model & & & & \\
\hline & Importance & Pleasure & Sign & Risk probability \\
\hline Pleasure & 0.65 & & & \\
\hline Sign & 0.32 & 0.14 & & \\
\hline Risk probability & 0.73 & 0.52 & 0.09 & \\
\hline Risk importance & 0.67 & 0.56 & 0.08 & 0.87 \\
\hline Modified model & & & & \\
\hline Pleasure & 0.65 & & & \\
\hline Sign & 0.32 & 0.14 & & \\
\hline Risk probability & 0.76 & 0.51 & 0.14 & \\
\hline Risk importance & 0.67 & 0.55 & 0.12 & 0.88 \\
\hline
\end{tabular}

\section{Fitness}

Table 5 shows the findings in terms of the primary and modified models fitness. As seen from the table, although the primary measurement model faced several issues in aspects of the convergent and divergent validity, when it came to the goodness-of-fit, no defect was observed and all criteria were passed. Since model fitness was acceptable no modification was performed in this regard and the modifications included the elimination of items 11 and 15 .

It is worth mentioning that, in the present study, the authors also checked the scale in a situation assuming that RPR and RIM compose one dimension (naming perceived risk by Laurent and Kapfere), but the convergent and divergent validity of the model still faced some deficiencies. 
Table 5

Goodness of fit measures

\begin{tabular}{|lllll|}
\hline Fitness indicator & Suggested criteria & Obtained value & Result \\
\cline { 2 - 4 } & & Primary Model $\quad$ Modified Model & Primary Model $\quad$ Modified Model
\end{tabular}

\begin{tabular}{|lcccll|}
\hline \multicolumn{2}{|l|}{ Absolute fit indices } & & & & \\
\hline $\mathrm{X}^{2} / \mathrm{df}$ & $<3$ & 1.584 & 1.826 & Compliant & Compliant \\
\hline $\mathrm{RMSEA}$ & $<0.05-0.08$ & 0.041 & 0.048 & Compliant & Compliant \\
\hline $\mathrm{PNFI}$ & $>0.5$ & 0.700 & 0.667 & Compliant & Compliant \\
\hline Incremental fit indices & & & & \\
\hline $\mathrm{NFI}$ & $>0.90$ & 0.893 & 0.906 & Compliant & Compliant \\
\hline $\mathrm{CFI}$ & $>0.90$ & 0.957 & 0.954 & Compliant & Compliant \\
\hline $\mathrm{IFI}$ & 0.958 & 0.955 & Compliant & Compliant \\
\hline Parsimonious fit indices & $>0.90$ & & & & \\
\hline GFI & $>0.90$ & 0.950 & 0.953 & Compliant & Compliant \\
\hline AGFI & 0.928 & 0.927 & Compliant & Compliant \\
\hline
\end{tabular}

\section{Discussion}

The CIP has been tested in several fields, but none of them have addressed the pharmaceutical area; this is while the consumer involvement can cause considerable challenges for policymakers of this domain. Therefore, the provision of a credible tool to measure involvement to pharmaceutical products is required. Considering this issue, this study was dedicated to assess the reliability, validity and fitness of the Persian version of CIP in the mentioned area.

The findings of the present study, confirm the good fitness of the scale developed by Laurent and Kapfere [11], after translation of the items from English into Persian and their refinement to adapt them to the pharmaceutical field. Content validity was also approved, based on the experts' opinions. However, when it came to the reliability and construct validity, several issues arose. These issues were not specific to the present study and have been reported in the previous researches applying CIP in some other fields. In the present research, deficiency of divergent validity was observed among importance, risk probability and risk importance, and also among importance and pleasure, if MSV, ASV and Fornell-Larcker get as the criteria to judge. However, HTMT values were all less than 0.9 and only in conservative situations some concerns may be raised regarding the discriminant validity of risk probability and risk importance. In previous studies, such as Laurent and Kappfer's research conducted in dresses, bras, washing machines, TV sets, vacuum cleaners, irons, champagne, oil, yoghurt, chocolate, shampoo, toothpaste, facial soap and detergent fields in 1985, overlap was observed between dimensions risk importance and risk probability but they believed that these dimensions are different theoretically and must be retained as independent facets [6]. The factor analysis of the Consumer Involvement Questionnaire (CIP) showed that the concept of involvement has different dimensions and each of these dimensions carries some part of information and consumer involvement cannot be measured in one dimension. However, based on what was observed in terms of the convergent and divergent validity, further research and some changes are needed to fix problems related to these aspects.

Regarding the risk probability, it seems to the authors that, in the field of medicines, many people do not have accurate information about the difference between the products of the same medicine manufactured by various pharmaceutical companies. In a similar way, their mindset of risk probability is not very clear and robust.

Turning next to the risk importance dimension, it can be say that it is strongly influenced by the importance of medication in one's mind and life. Therefore, it is highly probable that this concept be in the correlation with the "importance" dimension. In addition, the importance of the producer stability differs depending the type of disease; in some illnesses, change in the medicine producer can have considerable impact on the treatment outcomes, while in some others, it is not important. In the case of the former diseases, it is not far from mind that the respondent perceived high levels of risk probability and risk importance. These issues can affect the covariance and correlation among these two dimensions. Besides this the first authors developing the CIP scale, i.e. Laurent and Kapfere, pointed out the closeness of these two concepts and explained that they are two sub-dimensions of the more general concept of perceived risk [6].

A similar situation was reported in the Gursoy and Gavcar's study, conducted in 2003. This international research examined the CIP scale in the tourism field; its results supported the multidimensional construct of involvement. However, it did not reveal the exact factors discussed by Laurent and Kapferer; Gursoy and Gavcar elicited three dimensions from their data and suggested that the consumer involvement has three dimensions in leisure and tourism. In their study, importance and pleasure were overlapped and they concluded that, in leisure and tourism business, importance and pleasure are 
synonyms. In addition, they eliminated the sign dimension because its items had cross-loading with other constructs [16]. The results of the present study were in align with Gursoy and Gavcar 's finding in terms of importance and pleasure correlation. Such a result is not odd in the field of medicines, because these products set in the concept of mandatory purchase and in a majority of cases, people have to buy them in unpleasant conditions.

Consequently, pleasure has not true meaning in this field and is very close to the concept of importance.

Discussing the convergent validity and reliability problems found in the present study, it must be reminded that deficiencies in these aspects were also reported in previous literature, such as Gursoy and Gavcar's study; where several items held factor loadings less than 0.5 and Cronbach's alpha was lower than 0.7 for risk probability and risk importance. Similar situation was observed in Madrigal et al's study in 1992 that examined involvement with family vacations. They found only two strong dimensions including sign and importance/pleasure [25].

\section{Conclusions}

The results showed that the involvement measurement model based on CIP scale was of a good fitness. However, there are some concerns regarding its reliability and validity. The existing literature confirms that these concerns are not specific to the present study and the pharmaceutical field. Discussing the divergent validity, it can be said that based on the elicited HTMT values, the discriminant validity of CIP might be satisfying depending on the aims of the studies. If the aim of the study is measuring the whole consumer involvement, it seems proper. However, if discriminating various dimensions is important in a research, further studies are needed to develop a tool with such properties.

\section{Abbreviations}

AGFI: The adjusted goodness of fit index

ASV: Average Shared Squared Variance

AVE: Average Variance Extracted

CIP: Consumer Involvement Profile

CFA: Confirmatory Factor Analysis

CFI: comparative fit indices

CR: Composite Reliability

CVI: Content Validity Index

GFI: The goodness of fit index

HTMT: Heterotrait-monotrait ratio of correlations

IFI: the Incremental Fit Index

KMO: Kaisere-Meyere-Olkin

MSV: Maximum Shared Squared Variance

NFI: The normed fit index

PII: Personal Involvement Inventory

RFI: the Relative Fit Index

RMSEA: Root Mean Square Error of Approximation

TLI: Tucker-Lewis index

\section{Declarations}

\section{Ethics approval and consent to participate}

The study was approved by the Ethics Committee of Hamadan University of Medical Sciences (Code: IR.UMSHA.REC.1398.093). In the present study, a consent form was provided that informed the participants about the anonymity of the questionnaire, the aim of the study, optional participation in the study and responses confidentiality. Informed consent was obtained from all subjects and/or their legal guardian. The informed consent procedure for illiterate participants was approved by the above-mentioned ethics committee. 
Methods compatibility with guidelines and regulations

The authors confirm that all methods were performed in accordance with the relevant guidelines and regulations.

\section{Consent for publication}

Not applicable.

\section{Availability of data and materials}

The datasets generated and/or analysed during the current study are not publicly available due some parts of the findings were not in the scope of the present manuscript and have yet to be published. However, the dataset is available from the corresponding author on reasonable request.

\section{Competing interests}

The authors declare that they have no competing interests.

\section{Funding}

This research was supported by funding from the vice-chancellor for research and technology, Hamadan University of Medical Sciences, Hamadan, Iran (Grant number: 9803071919). The funding body had no role in the design of the study, collection, analysis, interpretation of data and writing the manuscript.

\section{Authors' contributions}

FM participated in data gathering and manuscript drafting. MR performed the study design, data analyses and manuscript revision. MM and SA had role in designing the study. All authors approved the final manuscript.

\section{Acknowledgements}

Not applicable.

\section{References}

1. Havitz ME, Dimanche F. Leisure involvement revisited: Drive properties and paradoxes. Journal of leisure research. 1999;31(2):122-49. https://doi.org/10.1080/00222216.1999.1194985 4.

2. Broderick AJ, Mueller RD. A theoretical and empirical exegesis of the consumer involvement construct: The psychology of the food shopper. Journal of Marketing Theory and Practice. 1999;7(4):97-108. https://doi.org/10.1080/10696679.1999.11501855.

3. Dimanche F, Samdahl D. Leisure as symbolic consumption: A conceptualization and prospectus for future research. Leisure Sciences. 1994;16(2):119-29. https://doi.org/10.1080/0 1490409409513224.

4. Rothschild ML. Perspectives on involvement: current problems and future directions. ACR North American Advances. 1984.

5. Zaichkowsky JL. Measuring the involvement construct. Journal of consumer research. 1985;12(3):341-52. https://doi.org/10.1086/208520.

6. Laurent G, Kapferer J-N. Measuring consumer involvement profiles. Journal of marketing research. 1985;22(1):41-53. https://doi.org/10.1177/002224378502200104.

7. Havitz ME, Dimanche F. Leisure involvement revisited: Conceptual conundrums and measurement advances. Journal of leisure research. 1997;29(3):245-78. https://doi.org/10.1080 /00222216.1997.11949796.

8. Jamrozy U, Backman SJ, Backman KF. Involvement and opinion leadership in tourism. Annals of tourism research. 1996;23(4):908-24.

9. Mittal B, Lee M-S. Separating brand-choice involvement from product involvement via consumer involvement profiles. ACR North American Advances. 1988.

10. Mittal B. A comparative analysis of four scales of consumer involvement. Psychology \& marketing. 1995;12(7):663-82. https://doi.org/10.1002/mar.4220120708.

11. Rodgers WC, Schneider KC. An empirical evaluation of the Kapferer-Laurent consumer involvement profile scale. Psychology \& Marketing 1993;10(4):333-45. https://doi.org/10.100 2/mar.4220100407.

12. Bloch PH. Involvement with adornments as leisure behavior: An exploratory study. Journal of Leisure Research. 1993;25(3):245-62. https://doi.org/10.1080/00222216.1993.11969924.

13. Dimanche F, Havitz ME, Howard DR. Testing the involvement profile (IP) scale in the context of selected recreational and touristic activities. Journal of leisure research. 1991;23(1): 51-66. https://doi.org/10.1080/00222216.1991.11969843.

14. Jain K, Srinivasan N. An empirical assessment of multiple operationalizations of involvement. ACR North American Advances. 1990.

15. Kim S-S, Scott D, Crompton JL. An exploration of the relationships among social psychological involvement, behavioral involvement, commitment, and future intentions in the context of birdwatching. Journal of Leisure Research. 1997;29(3):320-41. https://doi.org/10.10 
80/00222216.1997.11949799.

16. Gursoy D, Gavcar E. International leisure tourists' involvement profile. Annals of tourism research. 2003;30(4):906-26. https://doi.org/10.1016/S0160-7383(03)00059-8.

17. Abdo-Rabbo A, Al-Ansari M, Gunn BC, Suleiman BJ. The use of medicines in Oman: public knowledge, attitudes and practices. Sultan Qaboos University Medical Journal. 2009;9(2):124.

18. Mason P. One is okay, more is better? Pharmacological aspects and safe limits of nutritional supplements. Proceedings of the Nutrition Society. 2007;66(4):493-507. https://doi.org/10.1017/S0029665107005812. Cited in Altamimi M, Hamdan M, Badrasawi M, Allahham S. Knowledge, Attitudes and Practices Related to Dietary Supplements Amongst a Group of Palestinian Pharmacists. Sultan Qaboos University Medical Journal [SQUMJ]. 2021. https://doi.org/10.18295/squmj.4.2021.029.

19. Buelow M. Risky decision making in psychological disorders. 1st ed. London. UK: Academic Press; 2020. Pp. 39-59.

20. Guttman L. A basis for analyzing test-retest reliability. Psychometrika. 1945;10(4):255-82.

21. Waltz CF, Bausell RB. Nursing research: Design, statistics, and computer analysis: FA Davis company; 1981.

22. Shi J, Mo X, Sun Z. Content validity index in scale development. Zhong nan da xue xue bao Yi xue ban= Journal of Central South University Medical sciences. 2012;37(2):152-5. https:// doi.org/10.3969/j.issn.1672-7347.2012.02.007

23. Polit DF, Beck CT, Owen SV. Is the CVI an acceptable indicator of content validity? Appraisal and recommendations. Research in nursing \& health. 2007;30(4):459-67. https://doi. org/10.1002/nur.20199

24. Roemer E, Schuberth F, Henseler J. HTMT2-an improved criterion for assessing discriminant validity in structural equation modeling. Industrial Management \& Data Systems. 2021.

25. Madrigal R, Havitz ME, Howard DR. Married couples' involvement with family vacations. Leisure Sciences. 1992;14(4):287-301. https://doi.org/10.1080/00222216.1999. 11949854

\section{Figures}
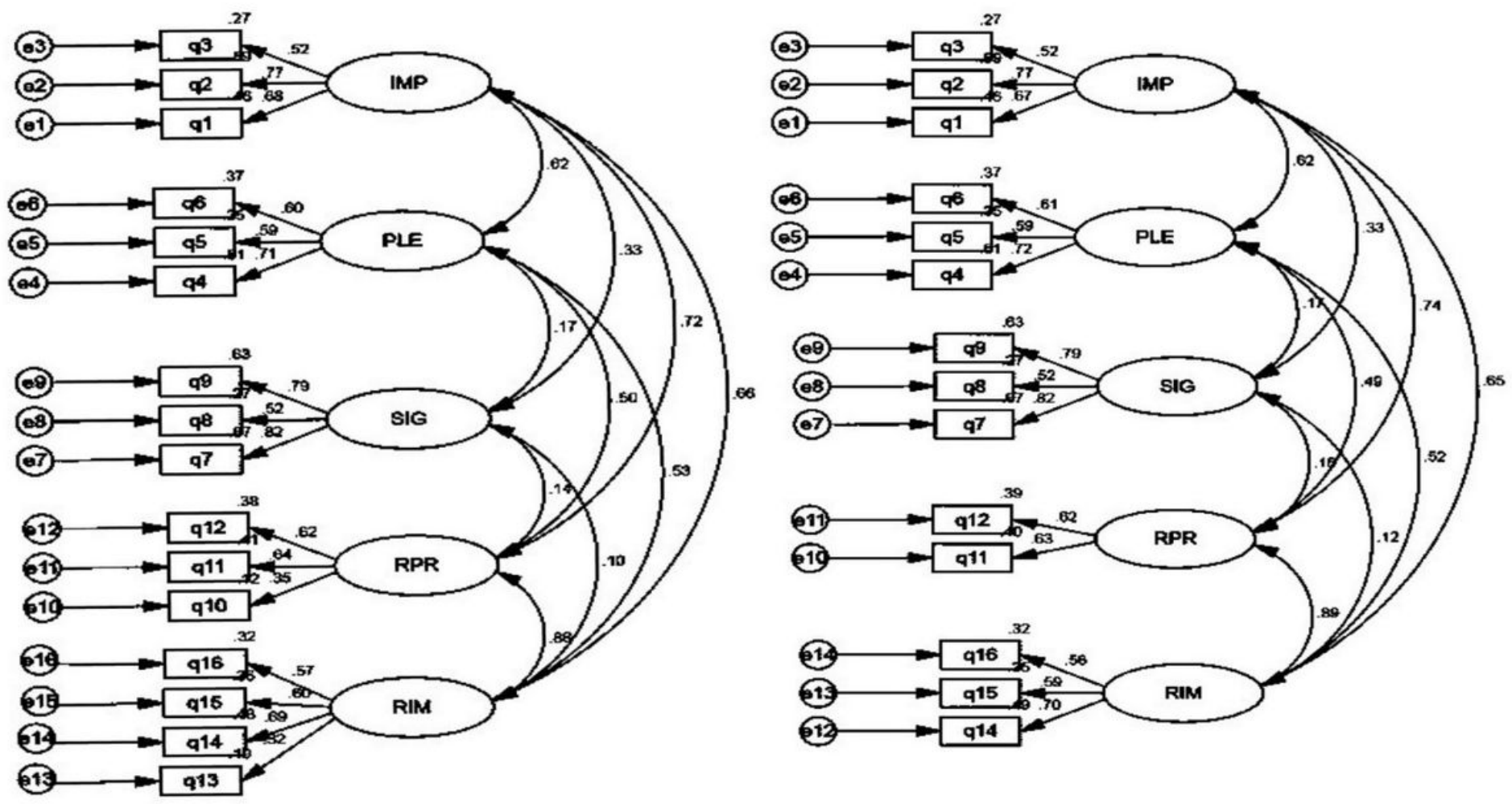

A

B

Figure 1

The primary (a) and modified (b) CFA model. 